\title{
HUBUNGAN PENGETAHUAN DAN SIKAP ORANG TUA TENTANG PENYAPIHAN DINI TERHADAP KEJADIAN STUNTING PADA BALITA DI PUSKESMAS KEDUNG BANTENG KAB.BANYUMAS
}

\author{
Ikhwah Mu'minah ${ }^{1}$ \\ Program Studi Kebidanan DIII Fakultas IImu Kesehatan \\ Universitas Muhammadiyah Purwokerto \\ Email: ikhwananda@gmail.com
}

\begin{abstract}
ABSTRAK
Pola penyapihan yang terlalu dini pada usia 0-6 bulan memunculkan masalah pada aspek hubungan sebab-akibat dimana pemberian MP-ASI yang kurang tepat mengakibatkan bayi menjadi gizi kurang atau gizi buruk. Pada usia 0-6 bulan, sebaiknya bayi hanya di diberi ASI secara eksklusif, karena produksi ASI pada usia tersebut sudah mencukupi kebutuhan gizi bayi untuk tumbuh kembang dan menjaga kesehatannya. Salah satu faktor yang mempengaruhi penyapihan dini diantaranya pengetahuan dan sikap orang tua. Penelitian ini merupakan jenis penelitian kuantitatif dengan desain studi cross sectional. Pengambilan sampel menggunakan tekhnik total sampling. Penelitian didapatkan bahwa adanya hubungan antara pengetahuan dan sikap orang tua tentang penyapihan dini terhadap kejadian stunting pada balita dengan $p$ value $<0,05$.

Kata Kunci: Penyapihan Dini, Pengetahuan, Sikap Orang Tua, Stunting
\end{abstract}

\begin{abstract}
The pattern of weaning that is too early at the age of 0-6 months raises problems in the aspect of cause-effect relationships where the provision of MP-ASI which is not right causes the baby to become malnourished or malnourished. At the age of 0-6 months, babies should only be exclusively breastfed, because milk production at that age is sufficient to meet the nutritional needs of infants to grow and maintain their health. One of the factors that influence early weaning includes the knowledge and attitudes of parents and research. This research is a type of quantitative research with cross sectional study design. Sampling using total sampling techniques. The study found that there is a relationship between parents' knowledge and attitudes about early weaning against the incidence of stunting in infants with a $p$ value $<0.05$ Keywords: Early Weaning, Knowledge, Attitudes of Parents, Stunting
\end{abstract}




\section{PENDAHULUAN}

Indonesia saat ini masih menghadapi permasalahan gizi yang berdampak serius terhadap kualitas sumber daya masyarakat. Salah satu masalah gizi yang menjadi perhatian utama saat ini adalah masih tingginya balita pendek (stunting). Indonesia termasuk didalam 47 negara dari 122 negara yang mempunyai masalah stunting pada balita sebesar 37,2\% (Achadi, 2015).

Pada tahun 2015 Kementerian Kesehatan melaksanakan Pemantauan Status Gizi (PSG) dengan hasil terdapat $29 \%$ balita di Indonesia termasuk kategori pendek. Pada tahun 2016 stunting terdapat peningkatan mencapai $27,5 \%$. Menurut WHO, prevalensi balita pendek menjadi masalah kesehatan masyarakat jika prevalensinya $20 \%$ atau lebih. Hal ini berarti pertumbuhan yang tidak maksimal dialami oleh sekitar 8,9 juta anak Indonesia atau 1 dari 3 anak Indonesia mengalami stunting (Kementerian Desa, 2017).

Pembangunan kesehatan Indonesia dalam periode tahun 2015-2019 difokuskan pada empat program prioritas yaitu penurunan angka kematian ibu dan bayi, penurunan prevalensi balita pendek (stunting), pengendalian penyakit menular dan pengendalian penyakit tidak menular. Sasaran pada tahun 2025 mengurangi 40\% jumlah balita pendek (Kemenkes RI, 2017).

Pola penyapihan yang terlalu dini pada usia 0-6 bulan memunculkan masalah pada aspek hubungan sebab-akibat dimana pemberian MP-ASI yang kurang tepat mengakibatkan bayi menjadi gizi kurang atau gizi buruk. Selain itu pemberhentian pemberian ASI terlalu dini pada umur dibawah 6 bulan akan berakibat kurang gizi pada bayi tersebut. Pada usia 0-6 bulan, sebaiknya bayi hanya di diberi ASI secara eksklusif, karena produksi ASI pada usia tersebut sudah mencukupi kebutuhan gizi bayi untuk tumbuh kembang dan menjaga kesehatannya (Pambudi, 2017).

\section{METODE PENILITIAN}

Penelitian ini merupakan jenis penelitian kuantitatif dengan desain Cross Sectional. Pengumpulan data dan informasi antara variabel dependen dan independen dilakukan pada waktu yang sama. Penelitian cross sectional merupakan jenis penelitian yang berusaha mempelajari dinamika hubungan atau korelasi antara dampak dan efeknya. Pengambilan sampel dengan menggunakan teknik total sampling yang artinya mengambil sampel dari keseluruhan populasi dengan jumlah sampel 100 responden.

\section{HASIL DAN PEMBAHASAN}

Tabel 1.1 Karakteristik Subjek Penelitian

\begin{tabular}{lll}
\hline \multicolumn{1}{c}{ Karakteristik } & Jumlah (n) & $\%$ \\
\hline 1. Pengetahuan orangtua & & \\
Rendah & 87 & 87 \\
Tinggi & 13 & 13 \\
2. Sikap Orangtua & & \\
Negatif & 51 & 51 \\
Positif & 49 & 49 \\
\hline
\end{tabular}

Tabel 1.1 menyajikan gambaran karakteristik subjek penelitian. Berdasarkan tabel tersebut terlihat bahwa dari 100 subjek penelitian terdapat 13 orangtua (13\%) berpengetahuan tinggi tentang penyapihan dini, sebagian besar tenaga kesehatan (90 $\%)$ tidak mendukung penyapihan dini, sikap orangtua yang memiliki sikap positif terhadap penyapihan dini sebesar $49 \%$.

Hubungan karakteristik subjek dengan kejadian stunting disajikan pada tabel 1.2 berikut ini : 
Tabel 1.2 Hubungan Karakteristik Subjek terhadap Kejadian Stunting.

\begin{tabular}{lccc}
\hline & \multicolumn{2}{c}{ Stunting } & \multirow{2}{*}{$\begin{array}{c}\text { Nilai } \\
\left.\mathbf{p}^{*}\right)\end{array}$} \\
\cline { 2 - 4 } Karakteristik & Ya & Tidak & 0,001 \\
\hline $\begin{array}{l}\text { Pengetahuan } \\
\text { orangtua }\end{array}$ & & & \\
$\begin{array}{l}\text { Rendah } \\
\text { Tinggi }\end{array}$ & 43 & 5 & \\
2. & 7 & 45 & 0,035 \\
$\begin{array}{l}\text { Sikap } \\
\text { Orangtua }\end{array}$ & & & \\
$\begin{array}{l}\text { Negatif } \\
\text { Positif }\end{array}$ & 35 & 20 & \\
\hline
\end{tabular}

Sumber data primer

Keterangan :

*) Uji chi square

Berdasarka tabel 1.2 terlihat bahwa pengetahuan orang tua dan sikap orangtua tentang penyapihan dini berhubungan dengan kejadian stunting $(p<0,05)$.

Hasil analisis bivariabel disajikan pada tabel 1.3 berikut ini :

Tabel 1.3 Hubungan pengetahuan dan sikap orangtua tentang penyapihan dini dengan Kejadian Stunting

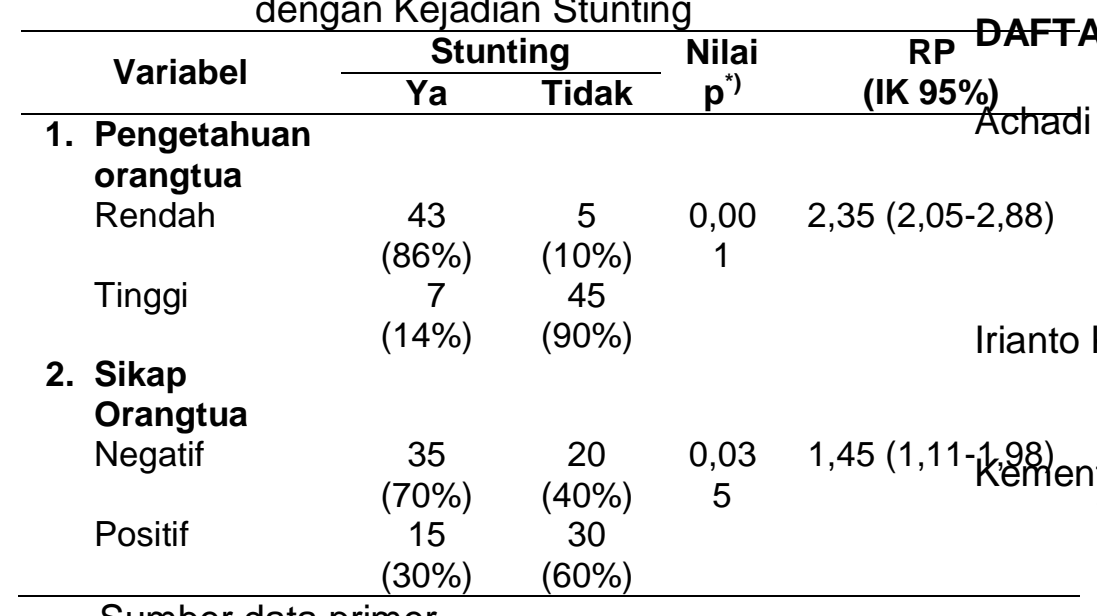

Sumber data primer

Kementerian Desa, Pembangunan Daerah Tertinggal, dan Transmigrasi. 2018. Buku Saku Kader Pembangunan Masnusia (KPM) Memastikan Konvergensi Penanganan Stunting Desa. Kemendes : Jakarta. hamil yang memiliki anak stunting sebesar $86 \%$ dan ibu hamil yang memiliki sikap negatif terhadappenyapihan dini memiliki anak stunting sebesar $70 \%$. Hasil perhitungan statistik tampak bahwa pengetahuan dan sikap memiliki hubungan yang bermakna dengan stunting, hasil ini dibuktikan dengan nilai $p<0,05$.

\section{KESIMPULAN}

Dari hasil analisis data dan pembahasan dapat disimpulkan bahwa karakteristik responden di puskesmas kedung banteng yaitu tingkat pengetahuan tinggi sebesar 87 $\%$ dan tingkat pengetahuan rendah $13 \%$ sedangkan sikap orang tua dalam penyapihan dini yang bersikap negatif sebanyak $51 \%$ dan bersikap positif sebanyak $49 \%$. Hasil analisi uji chi square sebesar 0,001 dan 0,035 yang berarti nilai $p<0,05$. Hal ini menunjukan adanya hubungan antara pengetahuan dan sikap orang tua tentang penyapihan dini terhadap kejadian stunting pada balita FKM UI : Jakarta. Tertinggal, dan Transmigrasi. 2017. Buku Saku Desa dalam Penanganan Stunting. Kemendes : Jakarta.
Berdasarkan tabel 1.3 terlihat bahwa ibu yang memiliki pengetahuan rendah
Keterangan :

*Uji chi-square: RP (IK 95\%) : Rasio Prevalen dan Interval Kepercayaan 95\%.

journal.umbjm.ac.id/index.php/midwiferyandreproduction 
Kementerian Kesehatan RI. 2018. Data dan Informasi Profil Kesehatan Indonesia 2017. Kemenkes RI: Jakarta

Kementerian Kesehatan RI. 2016. Situasi Balita Pendek. Jakarta : Kemenkes RI.

Marmi. 2012. ASI Saja Mama...: Berilah Aku ASI Karena Aku Bukan Anak Sapi: PanduanLengkap Manajemen Laktasi. Pustaka Pelajar : Yogyakarta

Mitayani, Sartika W. 2010. Buku Saku IImu Gizi. Trans Info Media: Jakarta

Nugroho. Konsep Penyapihan. Yogyakarta: Pustaka Pelajar, 2011

Pambudi J, Christijani R. 2017. Praktek Penyapihan Dini serta Huungannya dengan Keadaan Sosial Ekonomi dan Wilayah Tempat Tinggal. Penelitian Gizi dan Makanan: Desember Vol.40(2): 87-94.

Proverawati A, Wati EK. 2010. IImu Gizi Untuk Keperawatan dan Gizi Kesehatan. Muha Medika: Yogyakarta

Riskesdas. 2018. Hasil Utama Riskesdas 2018. Kementerian Kesehatan Badan Penelitian dan Pengembangan Kesehatan : Jakarta.

Rohmah E \& Sina JM. Faktor-Faktor Yang Mempengaruhi Kejadian Penyapihan Kurang Dari 2 Tahun Di Posyandu Sawahan Desa Sidodadi Kecamatan Mejayan Kabupaten Madiun. 2014;2(1):33-40.

Sutomo B, Anggraini DY. 2010. Menu Sehat Alami Untuk Balita dan Batita. PT. Agromedia Pustaka: Jakarta

World Breastfeeding Week. 2016. Mencegah Kekuranan Gizi pada 